\title{
Axial length elongation in adults with long-standing unilateral traumatic cataract
}

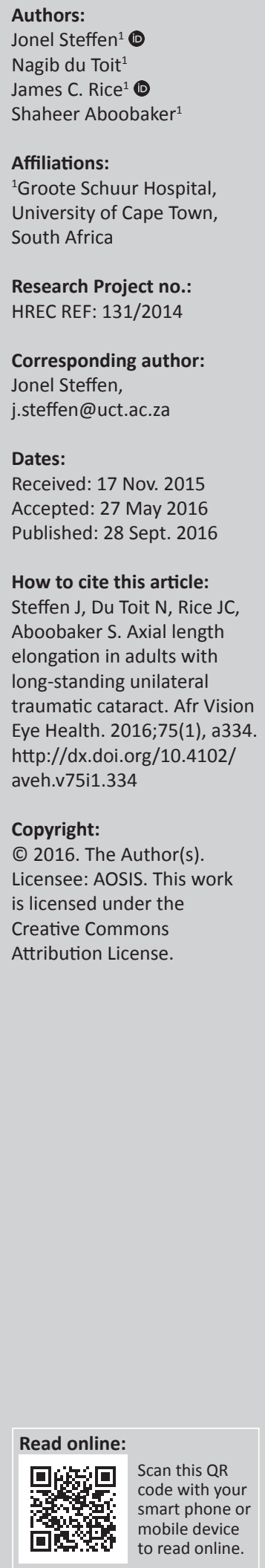

Background: Unilateral eye elongation with resultant axial myopia has been reported to occur secondary to visual deprivation from birth or early childhood. Acquired axial length elongation secondary to visual deprivation in adults has rarely been reported.

Aim: To report acquired axial myopia in adults with visual deprivation due to long-standing unilateral traumatic cataract.

Methods: Eleven consecutive adult patients who presented for cataract surgery with unilateral, long-standing, mature, traumatic cataracts and an interocular axial length difference of more than $1 \mathrm{~mm}$ were studied. Patients with a post-operative best corrected visual acuity (BCVA) of $<6 / 12$ were excluded to rule out possible pre-existing anisometropic amblyopia.

Results: Of the 11 patients with significant interocular axial length difference, 5 patients were excluded on the basis of possible pre-existing amblyopia. The remaining 6 patients had final BCVA of $6 / 12$ or better. The median length of the cataractous eyes was $2.83 \mathrm{~mm}$ longer than the fellow eyes (range $1.12 \mathrm{~mm}-3.52 \mathrm{~mm}$ ). The intraocular lens power required for emmetropia was 6.8 dioptres (range 3.5 dioptres - 11.5 dioptres) less in the cataractous eyes. A refractive outcome within 1 dioptre of the target refraction was achieved in all patients. The median delay between ocular trauma and cataract surgery was 20 years (range 8-24 years).

Conclusion: Significant unilateral axial length elongation may occur in adults with longstanding traumatic cataracts and visual deprivation. A potential correlation may exist between delay to surgery and degree of axial length difference. This rare phenomenon must be considered when determining intraocular lens power to avoid post-operative refractive surprises.

\section{Introduction}

Refractive accuracy is important for patient satisfaction after cataract surgery. A large interocular axial length difference on biometry raises the suspicion of a measurement error. This occurs more commonly with unilateral mature cataracts due to the reduced accuracy of biometry. ${ }^{1}$ In the absence of a history of anisometropia, it may be difficult to decide whether there is true anisometropia or whether there has been a measurement error. Hence, the choice of intraocular lens (IOL) power may be challenging.

Unilateral eye elongation with resultant axial myopia has been reported to occur secondary to visual deprivation. This has been described in animal models including primates, ${ }^{2,3,4}$ chicks, ${ }^{5}$ tree shrews $^{6}$ and other lower species. ${ }^{7,8}$ Several authors have described axial length elongation in humans with unilateral visual deprivation from birth or early childhood, $, 10,11,12,13$ but reports of this phenomenon in adults are uncommon. At the time of our review, we found only one such study on adults in the English literature. ${ }^{14}$

The aim of our study is to describe significant unilateral axial myopia in eyes with long-standing visual deprivation due to traumatic cataract. The increase in axial length may be on the basis of visual deprivation.

\section{Research methods and design}

This retrospective case series comprised consecutive adult patients who presented with unilateral mature traumatic cataracts and an interocular axial length difference of more than $1 \mathrm{~mm}$. The study was conducted at the Department of Ophthalmology, Groote Schuur Hospital, University of Cape Town, between November 2009 and October 2013 and was approved by the institutional ethics committee (HREC REF: 131/2014). 
TABLE 1: Trauma history, biometric data, visual and refractive outcome.

\begin{tabular}{|c|c|c|c|c|c|c|c|c|c|c|c|c|c|}
\hline \multirow[t]{2}{*}{$\begin{array}{l}\text { Patient } \\
\text { number }\end{array}$} & \multicolumn{2}{|c|}{ Age (years) } & \multirow[t]{2}{*}{$\begin{array}{l}\text { Delay } \\
\text { (years) }\end{array}$} & \multicolumn{2}{|c|}{ Axial length (mm) } & \multicolumn{2}{|c|}{ Average K (dioptre) } & \multicolumn{2}{|c|}{$\begin{array}{c}\text { IOL for emmetropia } \\
\text { (dioptre) }\end{array}$} & \multirow[t]{2}{*}{$\begin{array}{l}\text { IOL used } \\
\text { (dioptre) }\end{array}$} & \multirow{2}{*}{$\begin{array}{c}\text { Preoperative } \\
\text { BCVA } \\
\text { (Snellen) }\end{array}$} & \multirow{2}{*}{$\begin{array}{c}\text { Post- } \\
\text { operative } \\
\text { BCVA } \\
\text { (Snellen) }\end{array}$} & \multirow{2}{*}{$\begin{array}{l}\text { Post-operative } \\
\text { spherical } \\
\text { equivalent } \\
\text { (dioptre) }\end{array}$} \\
\hline & Injury & Surgery & & $\begin{array}{c}\text { Cataractous } \\
\text { eye }\end{array}$ & $\begin{array}{l}\text { Fellow } \\
\text { eye }\end{array}$ & $\begin{array}{c}\text { Cataractous } \\
\text { eye }\end{array}$ & $\begin{array}{l}\text { Fellow } \\
\text { eye }\end{array}$ & $\begin{array}{l}\text { Cataractous } \\
\text { eye }\end{array}$ & $\begin{array}{l}\text { Fellow } \\
\text { eye }\end{array}$ & & & & \\
\hline 1 & 16 & 34 & 18 & 25.64 & 23.38 & 43.75 & 43.87 & 13.5 & 20.0 & 15.0 & $\mathrm{CF}$ & $6 / 9$ & Not recorded \\
\hline 2 & 19 & 27 & 8 & 23.66 & 22.54 & 44.75 & 44.75 & 18.5 & 22.0 & 19.0 & $\mathrm{HM}$ & $6 / 5$ & -0.50 \\
\hline 3 & 9 & 30 & 21 & 27.14 & 24.34 & 41.25 & 42.00 & 12.0 & 19.0 & 12.0 & HM & $6 / 12$ & -1.00 \\
\hline 4 & 27 & 41 & 14 & 27.42 & 23.90 & 43.75 & 43.25 & 8.0 & 19.5 & 10.0 & $\mathrm{CF}$ & $6 / 6$ & -0.25 \\
\hline 6 & 29 & 53 & 24 & 30.42 & 27.51 & 42.25 & 42.50 & 3.0 & 9.5 & 5.0 & $\mathrm{CF}$ & $6 / 9$ & -1.25 \\
\hline
\end{tabular}

$\mathrm{K}$, keratometry; IOL, intraocular lens; BCVA, best corrected visual acuity; CF, counting fingers; HM, hand motion.

Preoperative assessment included an ophthalmic history with emphasis on the timing of the ocular injury and visual loss. Distance best corrected visual acuity (BCVA), slitlamp examination findings and intraocular pressure were recorded. Fundus examination was not possible due to the maturity of the cataracts, and B-scan ultrasonography was performed to exclude posterior segment pathology. Axial length was measured by immersion ultrasonography with an Ocuscan $\mathrm{RxP}$ biometer (Alcon Laboratories, Inc.). Keratometry was conducted using a Nidek (Genop Holdings Pty Ltd.) or Huvitz (Eurotech Optical) autorefractor/keratometer. The SRK-T formula was used for IOL calculation.

Phacoemulsification with implantation of a posterior chamber IOL in the capsular bag was performed on all patients, except for one case of extensive zonular dehiscence requiring an intracapsular cataract extraction, anterior vitrectomy and a scleral-fixated posterior chamber IOL. Postoperative BCVA, refraction and any fundus abnormalities were recorded.

Data analysis was performed using Stata version 12 statistical software. ${ }^{15}$ Linear regression analysis was used to evaluate the relationship between delay to cataract surgery and degree of interocular axial length difference and was considered statistically significant if the $p$ value was $<0.05$.

\section{Results}

Eleven adult patients with long-standing, unilateral, mature traumatic cataracts and an interocular axial length difference of more than $1 \mathrm{~mm}$ were identified. Five patients had a postoperative BCVA of $<6 / 12$ and normal fundoscopy. Even though these patients all gave a history of good vision prior to the development of their cataract, they were excluded to rule out the possibility of pre-existing amblyopia due to myopic anisometropia. The remaining six patients had final visual acuity of $6 / 12$ or better, which we felt excluded preexisting amblyopia.

Age at time of injury, biometric data, visual and refractive outcomes of the remaining six patients are outlined in Table 1. Five patients had a history of blunt trauma to the cataractous eye, whilst one patient had a penetrating eye injury. The age at the time of ocular injury ranged from 9 to 29 years with a median of 18 years. The median delay between trauma and cataract surgery was 20 years (range 8-24 years). All the study eyes had mature, white cataracts with a BCVA of

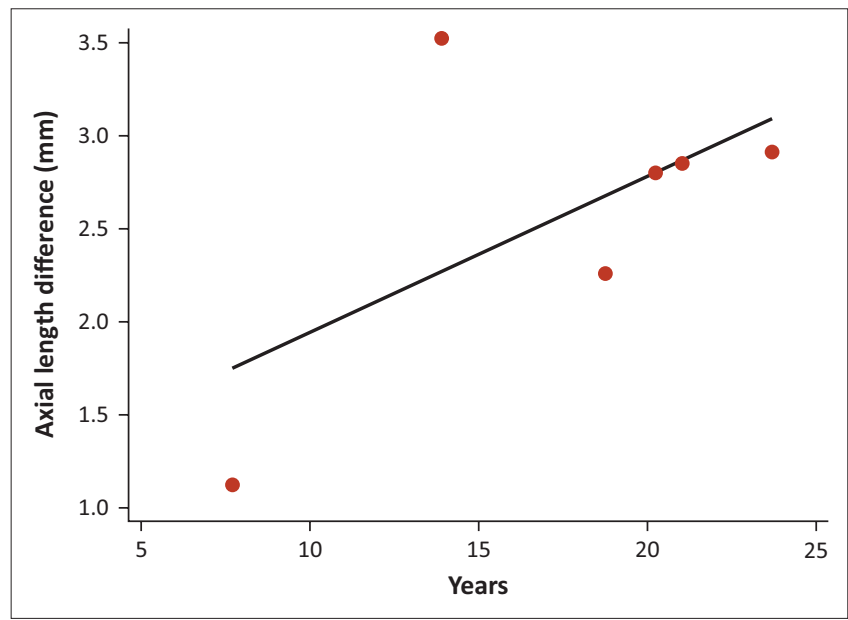

FIGURE 1: Correlation between delay to cataract surgery and interocular axial length difference.

counting fingers or hand motion. None of the patients had raised intraocular pressure or posterior segment abnormalities on B-scan ultrasonography.

The median length of the cataractous eyes was $2.83 \mathrm{~mm}$ longer than the fellow eyes (range $1.12 \mathrm{~mm}-3.52 \mathrm{~mm}$ ). This translated to a 6.8 dioptres (range 3.5 dioptres -11.5 dioptres) median difference in IOL strength for emmetropia. All six patients achieved a post-operative BCVA of $6 / 12$ or better, with a refractive outcome within 1 dioptre of the target refraction. One patient was lost to follow-up after the first post-operative visit and was not refracted. Her uncorrected distance visual acuity was $6 / 9$ on the first post-operative day.

Linear regression analysis suggested that each year delay in surgery was associated with an increase of $0.08 \mathrm{~mm}$ in axial length but the numbers were too small to be statistically significant $\left(95 \% \mathrm{CI}-0.25\right.$ to $0.41 ; p=0.41, R^{2}=0.47$ ) (Figure 1$)$.

\section{Discussion}

This case series presents adult patients with unilateral axial myopia in eyes with long-standing unilateral mature traumatic cataract. We propose that axial length elongation may have occurred due to long-standing visual deprivation despite the median age of 18 years at the time of visual loss.

This phenomenon has important clinical implications for correct IOL power selection during cataract surgery. In our study, the median IOL power for emmetropia was 6.8 dioptres 
less in the cataractous eyes than the fellow eyes. Since axial length measurements are known to be less accurate in eyes with mature cataracts, ${ }^{1}$ the surgeon may incorrectly select IOL power according to the biometry of the fellow eye. This would cause a myopic refractive surprise and require further intervention such as an IOL exchange. This has particular relevance in settings with limited resources.

Visual deprivation myopia is well described in animal

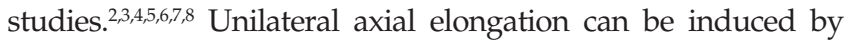
eyelid suturing, corneal opacification or opaque contact lenses in young animals of various species. In a study on monkeys, Smith et al. demonstrated that the earlier the deprivation is initiated and the longer it is maintained, the greater the degree of relative myopia produced in the visually deprived eye. ${ }^{4}$ In addition, Siegwart et al. found that the susceptible period for deprivationinduced myopia in tree shrews extends into adulthood. ${ }^{6}$

Several authors have described a similar phenomenon in humans with unilateral visual deprivation from birth or early childhood. Huo et al. found a higher frequency of ipsilateral myopia in patients with severe unilateral congenital ptosis (55.3\% ptotic eye vs. $37.6 \%$ control eye, $p=0.031) .{ }^{11}$ Calossi et al. examined 13 adult patients with unilateral traumatic infantile cataracts and demonstrated a greater axial length in the affected eye compared to the uninjured eye. ${ }^{9}$ Hooker et al. described monocular deprivation in an identical twin due to unilateral congenital cataract. By the age of 6 years, the involved eye developed a $3.9 \mathrm{~mm}$ elongation in axial length compared to the other eye and both eyes of the identical twin. ${ }^{10}$ Schellenbeck et al. and Mahler et al. reported the same phenomenon in infants with visual deprivation due to unilateral corneal scars. ${ }^{12,13}$

The only human study in the English literature describing this phenomenon in adults was published by Gradin et al. ${ }^{14}$ They performed a retrospective cohort study on 13 patients with unilateral traumatic cataracts for more than 1 year and an interocular axial length difference of more than $1 \mathrm{~mm}$. Study patients were found to have a significantly higher median interocular axial length difference $(3.09 \mathrm{~mm}$, interquartile range [IQR] $2.45 \mathrm{~mm}-4.13 \mathrm{~mm})$ than control patients $(0.24 \mathrm{~mm}$, IQR $0.15 \mathrm{~mm}-0.30 \mathrm{~mm}, p=0.000)$. An important limitation of their study was that poor visual outcome in nine (69\%) of their patients could be explained by pre-existing anisometropic amblyopia.

Afsari et al. reported that anisometropia of $>1$ dioptre in early childhood is significantly associated with amblyopia (OR 12.4, 95\% CI 4.0 to 38.4), and the risk increases with higher degrees of anisometropia. ${ }^{16}$ In our study, we excluded patients with post-operative BCVA of $<6 / 12$ to avoid the inclusion of patients with potential pre-existing myopic anisometropic amblyopia.

It appears that there may be a correlation between the delay to cataract surgery and the degree of interocular axial length difference. The trend was not statistically significant due to small numbers (Figure 1). Visual deprivation may be the cause of the axial length elongation even in adults. Gradin et al. did not find a similar correlation in their study of long-standing, unilateral traumatic cataracts $\left(R^{2}=0.0143\right)$, but noted that their study may have had too few patients to detect it. ${ }^{14}$ Therefore, further studies with larger sample sizes are needed.

Limitations of our study include small sample size and absence of intraocular pressure measurements in the period between trauma and cataract surgery. However, none of our study patients had an elevated intraocular pressure at the time of preoperative assessment, and no other features of glaucoma were present.

\section{Conclusion}

Unilateral axial length elongation may occur in adults with visual deprivation due to long-standing mature traumatic cataract. It is important to be aware of this rare phenomenon to facilitate correct IOL selection when performing cataract surgery on these patients.

\section{Acknowledgements Competing interests}

The authors declare that they have no financial or personal relationships which may have inappropriately influenced them in writing this article.

\section{Authors' contributions}

J.S. did the literature review, designed data collection tools and drafted the manuscript. She was the project leader. N.d.T. assisted with the literature review and revised the manuscript. J.C.R. did the statistical analysis and revised the manuscript. S.A. was responsible for data collection.

\section{References}

1. Freeman G, Pesudovs $K$. The impact of cataract severity on measurement acquisition with the IOL Master. Acta Ophthalmol Scand. 2005;83(4):439-442. http://dx.doi.org/10.1111/j.1600-0420.2005.00473.x

2. Wiesel TN, Raviola E. Increase in axial length of the macaque monkey after corneal opacification. Invest Ophthalmol Vis Sci. 1979;18(12):1232-1236.

3. Tigges $M$, Tigges J, Fernandes $A$, et al. Postnatal axial elongation in normal and visually deprived rhesus monkeys. Invest Ophthalmol Vis Sci. 1990;31(6):10351046.

4. Smith EL 3rd, Harwerth RS, Crawford ML, et al. Observations on the effects of form deprivation on the refractive status of the monkey. Invest Ophthalmol Vis Sci. 1987;28(8):1236-1245

5. McGlinn AM, Baldwin DA, Tobias JW, et al. Form-deprivation myopia in chicks induces limited changes in retinal gene expression. Invest Ophthalmol Vis Sci. 2007;48(8):3430-3436. http://dx.doi.org/10.1167/iovs.06-1538

6. Siegwart Jr JT, Norton TT. The susceptible period for deprivation-induced myopia in tree shrews. Vision Res. 1998;38(22):3505-3515. http://dx.doi.org/10.1016/ S0042-6989(98)00053-4

7. Shen $W$, Vijayan $M$, Sivak JG. Inducing form-deprivation myopia in fish. Invest Ophthalmol Vis Sci. 2005;46(5):1797-1803. http://dx.doi.org/10.1167/iovs.04-1318

8. Verolino $M$, Nastri $G$, Sellitti L, et al. Axial length increase in lid-sutured rabbits. Surv Ophthalmol. 1999;44, Supplement 1(0):S103-S108.

9. Calossi A. Increase of ocular axial length in infantile traumatic cataract. Optom Vis Sci. 1994;71(6):386-391. http://dx.doi.org/10.1097/00006324-199406000-00006

10. Hooker PJ, FitzGerald DE, Rutner D, et al. Monocular deprivation in an identical twin. Optometry. 2005;76(10):579-587. http://dx.doi.org/10.1016/j.optm.2005.07.004

11. Huo L, Cui D, Yang $X$, et al. A retrospective study: Form-deprivation myopia in unilateral congenital ptosis. Clin Exp Optom. 2012;95(4):404-409. http://dx.doi. org/10.1111/j.1444-0938.2012.00716.x

12. Schellenbeck M, Hartmann C, Schwarz EC. Formation of a unilateral form deprivation myopia due to a congenital eyelid entropium with a consecutive corneal ulcer: An illustrated case report. Strabismus. 2002;10(2):107-110. http:// corneal ulcer: An illustrated case report.
dx.doi.org/10.1076/stra.10.2.107.8126 
13. Mahler $\mathrm{O}$, Hoffman $\mathrm{P}$, Pollack $\mathrm{A}$, et al. Increase in posterior segment depth in eyes with corneal opacities. Harefuah. 2006;145(3):202-204.

14. Gradin D, Gichuhi S. Unilateral axial length elongation with chronic traumatic cataracts in young Kenyans. J Cataract Refract Surg. 2008;34(9):1566-1570. http://dx.doi.org/10.1016/j.jcrs.2008.05.035
15. Stata [statistical software]. Release 11. College Station, TX: StataCorp LP; 2011.

16. Afsari S, Rose KA, Gole GA, et al. Prevalence of anisometropia and its association with refractive error and amblyopia in preschool children. $\mathrm{Br}$ Ophthalmol. 2013;97(9):1095-1099. http://dx.doi.org/10.1136/bjophthalmol2012-302637 